\title{
ESTUDOS INTEGRADOS EM SUB-BACIAS DO CÓRREGO DO CEDRO, SP, ATRAVÉS DO MÉTODO CURVE NUMBER, PARA PLANEJAMENTO AMBIENTAL
}

\author{
José Roberto Amaro Mantovani ${ }^{(a)}$, Guilherme Taitson Bueno ${ }^{(b)}$, Gabriel Saavedra \\ Velenzuela $^{(\mathrm{c})}$, Adalto Braz Moreira ${ }^{(\mathrm{d})}$
}

\author{
(a) Geografia/Universidade Federal de Goiás/IESA, jr.mantovani.geo@gmail.com \\ (b) Geografia/Universidade Federal de Goiás/IESA, gtaitsonbueno@gmail.com \\ (c) Geografia/Universidade Federal de Goiás/IESA, valenzuelasg@gmail.com \\ (d) Geografia/Universidade Federal do Mato Grosso do Sul/CPTL, adaltobraz.geografia@gmail.com
}

\section{Eixo: GEOTECNOLOGIAS E MODELAGEM ESPACIAL EM GEOGRAFIA FÍSICA}

\begin{abstract}
Resumo
Este trabalho é a continuação de estudos geoambientais integrados em sub-bacias da bacia hidrográfica do córrego do Cedro/SP, localizada no município de Presidente Prudente/SP. Objetiva-se neste estudo analisar as condições atuais da bacia, tendo em vista a ocupação que vem se processando nos últimos anos devido o processo de desenvolvimento local e crescimento urbano do município, contemplando grandes loteamentos habitacionais e particulares de ocupação territorial, além de empreendimentos industriais e agroindustriais. Diante desse quadro de ocupação, questiona-se sobre os impactos positivos e negativos que estão sendo gerados a esse ambiente. Assim, este trabalho tem como objetivo realizar esses estudos, em escalas que permitam, posteriormente, subsidiar a preservação, controle e o monitoramento dos recursos naturais e da dinâmica ambiental, por meio de uma análise hidrológica, utilizando o método curva-número $(\mathrm{CN})$, para simular o padrão de escoamento superficial em sub-bacias do córrego do Cedro, dentro do perímetro urbano do município de Presidente Prudente/SP.
\end{abstract}

Palavras chave: Geoambiente. Análise hidrológica. Curva número. Escoamento superficial

\section{INTRODUÇÃO}

O crescimento dos centros urbanos afeta diretamente o ciclo hidrológico em um ambiente natural. Todavia, com a necessidade da expansão territorial urbana, ocorre a incorporação de novas áreas, englobando todos os tipos de compartimentos do relevo, sejam eles topos, vertentes, fundos de vales e/ou cabeceiras de drenagem. Em áreas rurais, as atividades agropecuárias se mostram como grandes responsáveis pela retirada da cobertura vegetal e pela geração dessas mudanças, em virtude da sua rápida expansão e tamanho das áreas que ocupam.

A cobertura vegetal sendo alterada afeta-se o ciclo hidrológico natural. Também a cobertura da bacia hidrográfica é transformada em pavimentos impermeáveis e o escoamento pluvial deve ser canalizado. Porém a redução da infiltração no solo, o volume de água que deixa de se infiltrar escoa pela superfície e o nível do lençol freático diminui por falta de recarga. Sem a cobertura natural vegetal ocorre ainda uma redução da evapotranspiração, para agravar ainda mais a situação (TUCCI, 2000), além de repercutir em diversos problemas nos recursos hídricos, como erosão superficial, 
OS DESAFIOS DA GEOGRAFIA FÍSICA NA FRONTEIRA DO CONHECIMENTO

Instituto de Geociências - Unicamp

Campinas - SP

28 de Junho à 02 de Julho de 2017

assoreamento de rios, lixiviação do solo, perda de disponibilidade e qualidade de água, entre outros problemas que irão repercutir nas atividades socioeconômicas.

A sub-bacia do córrego do Cedro localiza-se na área sul de Presidente Prudente; hidrograficamente faz parte da bacia do rio Santo Anastácio, importante afluente do rio Paraná. A ocupação da bacia do Santo Anastácio, na qual está inserido o referido manancial, foi bastante intensa a partir da segunda metade do século XX, agregando diversas atividades antrópicas e desmatamento em larga escala, devido à criação e expansão de conjuntos habitacionais (STEIN, 1999). Na confluência dos córregos do Cedro e Cedrinho há uma represa, acerca de $7 \mathrm{~km}$ ao sul da cidade. Esse reservatório já foi responsável por $70 \%$ do abastecimento de água do município, porém atualmente corresponde a apenas $30 \%$, sendo necessário recorrer ao reservatório do rio do Peixe, localizado a $40 \mathrm{~km}$ de distância da estação de tratamento de água (DIBIESO, 2007).

Recentemente, novas áreas situadas na sub-bacia do Cedro estão sendo incorporadas ao processo de desenvolvimento local e crescimento urbano do município de Presidente Prudente/SP, contemplando grandes loteamentos habitacionais e particulares, aberturas de estradas, expansão das fronteiras agrícolas, programas de assentamento rural, além de empreendimentos industriais e agroindustriais. Diante desse quadro de ocupação questiona-se sobre os impactos positivos e negativos que estão sendo gerados na bacia do Cedro, especificamente na zona noroeste da bacia, correspondendo ao setor mais urbanizado dessa bacia ao qual recentemente, novas áreas estão sendo incorporadas.

Assim, neste trabalho tem-se como objetivo realizar estudos hidrológicos, em escalas que permitam, posteriormente, subsidiar a preservação, controle e o monitoramento dos recursos naturais e da dinâmica ambiental. Isso será realizado por meio de uma análise hidrológica, utilizando o método curva-número $(\mathrm{CN})$, para simular o comportamento de escoamento superficial espacialmente distribuído, em sub-bacias do córrego do Cedro, dentro do perímetro urbano do município de Presidente Prudente/SP, especificamente para o ano de 2016, em razão dos dados preestabelecidos para pesquisa, de modo a simular a dinâmica atual, de parte dos processos atuantes nessa escala, tempo e espaço.

\section{Metodologia}

\section{1 Área de Estudo}

A área de estudo localiza-se no Estado de São Paulo, na região sudeste do município de Presidente Prudente e possui uma área de aproximadamente de 1.256 hectares, com altitude que varia entre $358 \mathrm{a}$ 472 metros, servida pelas rodovias Júlio Budisk, Comendador Alfedro Bonfigliori, SP-501, e pela avenida Miguel Dhama, compreendendo os bairros Mário Amato, Ana Jacinta, Jardim Novo Prudentino, Uep4-S.1, Uep8-S.2, residencial Dhama (I, II e III) e, mais recentemente, o loteamento Campos do Conde (Figura 1). 


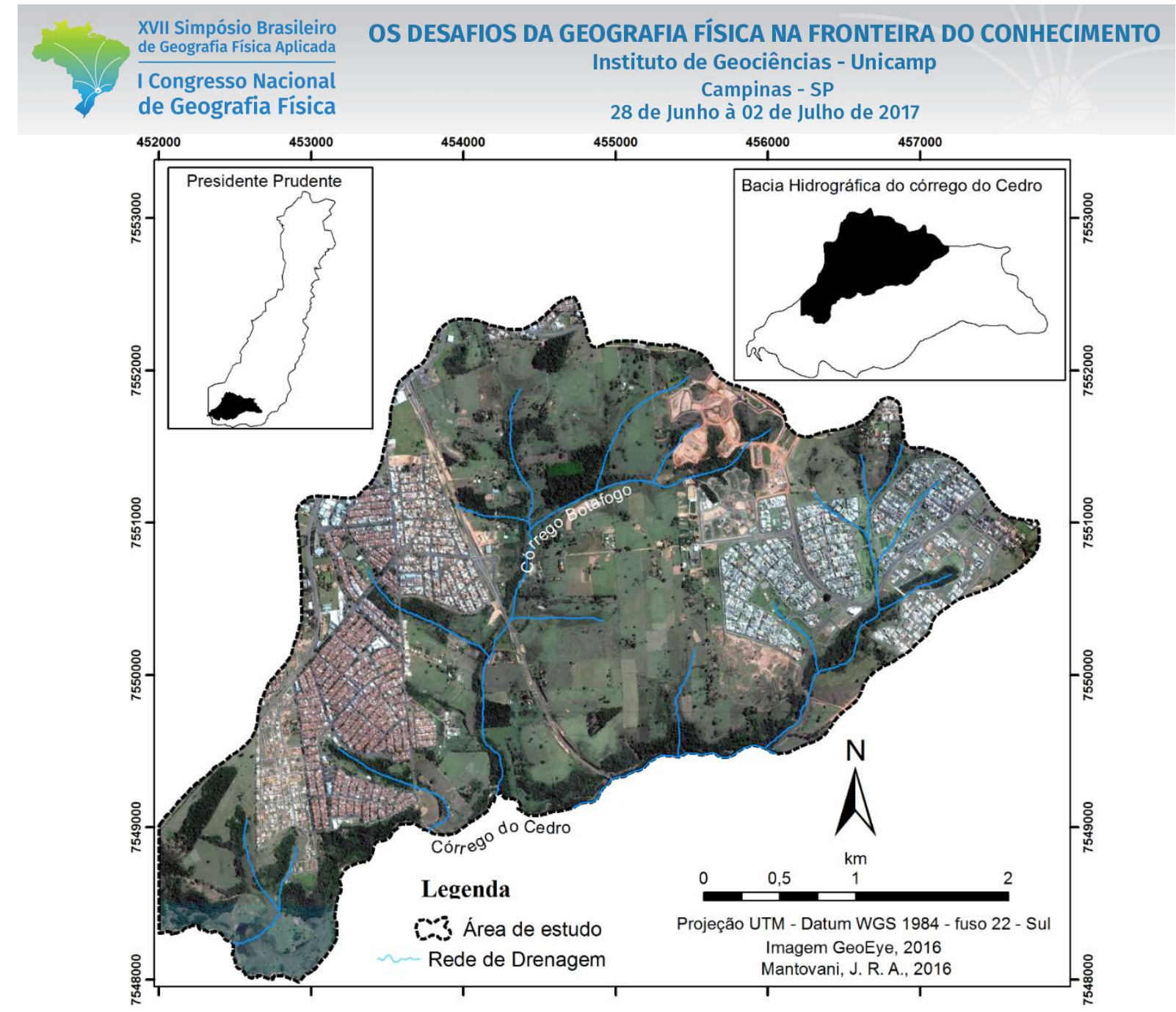

Figura 1. Localização da área de estudo.

A Formação florestal original na bacia do córrego do Cedro é classificada como Floresta Tropical Semidecidual, contida na classificação fisionômico-ecológica da formação ecológica do Sudeste Paulista (FRANCISCO, 1989).

Geomorfologicamente, o município de Presidente Prudente, está situado na morfoestrutura da Bacia Sedimentar do Paraná e na morfoescultura do Planalto Ocidental Paulista, mais precisamente no Planalto Centro Ocidental, formado essencialmente por rochas do Grupo Bauru, sobretudo arenitos. As formas de relevo predominantes são as colinas amplas e baixas com altimetria entre 300 e 600 metros e declividades que variam de 10 a $20 \%$ (Nunes et al. 2006).

A sazonalidade climática pode ser resumida a um período quente e chuvoso entre outubro e março e, outro mais ameno e seco, entre abril e setembro, quando as temperaturas caem com a entrada das massas polares (BARRIOS; SANT'ANNA NETO, 1996).

\subsection{Metodologia}

A fundamentação teórico-metodológica que subsidiou o emprego das geotecnologias associadas a um sistema de informação geográfica (SIG) na modelagem do escoamento superficial espacialmente 
OS DESAFIOS DA GEOGRAFIA FISICA NA FRONTEIRA DO CONHECIMENTO

Instituto de Geociências - Unicamp

Campinas - SP

28 de Junho à 02 de Julho de 2017

distribuído, se baseou na análise integrada do ambiente apoiado no método Curve Number (1971), do Soil Conservation Service (SCS, 1971), atual Natural Conservation Service (UNSR, 2009).

A etapa inicial da pesquisa consistiu no levantamento de informações bibliográficas, cartográficas e iconográficas referentes à área de estudo. Após esse levantamento, foi criado um banco de dados geográficos, estruturado a partir das informações cartográficas obtidas da carta topográfica do município de Presidente Prudente, folha SF-22-Y-B-III-1, na escala de 1:50.000; dados digitais de elevação (DEM), com resolução espacial de 5 metros, provenientes do Projeto de Atualização Cartográfica do Estado de São Paulo - "Projeto Mapeia São Paulo" (EMPLASA, 2010). A área teste de estudo (área urbana 1.256 hectares) foi limitada apenas para as áreas onde se obtiveram os dados de curvas de nível $(5 \mathrm{~m})$, devido à disponibilidade; imagens de alta resolução espacial, provenientes do satélite GeoEye, na escala de 1: 2.000, datadas de agosto de 2016; os dados de solos para área de estudo foram obtidos do levantamento semidetalhado dos solos da bacia do rio Santo Anastácio/SP, elaborado por Carvalho (1997), na escala 1: 50.000. Sendo identificado na área: Neossolo Flúvico (Ae3), Gleissolo Háplico Distrófico (HGPa2); Argissolo Vermelho-Escuro (PEa4), Argissolo Vermelho-Amarelo (PVa4) e Argissolo-Vermelho (PVe6); dados de precipitação obtidos através do Centro integrado de informações agrometereológicas (CIIAGRO).

Este conjunto de dados foi organizado dentro do ambiente SIG, com auxílio da plataforma HECGeoHMS (Geospatial Hydrologic Modeling Extension), pertencente ao United Army Corps of Enginners.

\subsection{Estimativa do Escoamento Superficial}

A modelagem do escoamento superficial (Q) seguiu os procedimentos teóricos metodológicos descritos por Tucci (2001), por meio do método Curve Number (CN). No método CN, a estimativa de escoamento superficial $(Q, \mathrm{~mm})$ é realizada de acordo com a Equação 1.

$$
Q=\frac{(P-0,2 \times S)^{2}}{P+0,8 \times S}
$$

Onde $\mathrm{P}$ corresponde à precipitação efetiva $(\mathrm{mm}), \mathrm{S}$ é a capacidade máxima de armazenamento de água (saturação) da camada superior do solo na bacia hidrográfica (Equação 2). A Equação 1 somente é válida para $^{P>0.2 \times S}$ quando $P<0.2 \times S$, tem-se que $\mathrm{Q}=0$.

Neste trabalho considerou-se a precipitação efetiva (P), ou seja, que ocasionou o escoamento superficial através da intensidade pluviométrica (IP), obtida pela relação entre a precipitação média anual (PMA) e duração do período chuvoso (DPC), proposta por Crepani et al. (2001). Como o mapeamento de uso do solo e cobertura vegetal foi feito especificamente para o ano de 2016, a 


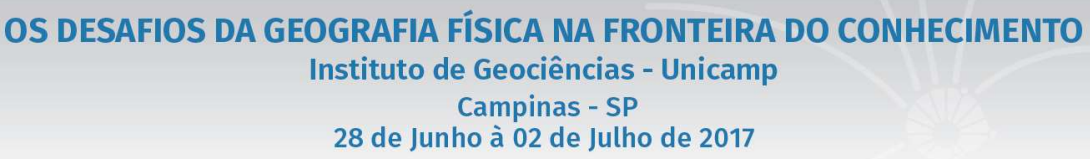

precipitação média anual (PMA) determinada seguiu a mesma escala de tempo, sendo de $1651.46 \mathrm{~mm}$ e a duração do período chuvoso de 6 meses (outubro a março). Assim, a IP obtida foi de 275,16 mm.

Para determinar a capacidade máxima de infiltração da camada superficial do terreno $(\mathrm{S})$, o método relaciona esse parâmetro com o fator de $\mathrm{CN}$ de acordo com a Equação 2.

$$
S=\left(\frac{25400}{C N}\right)-254
$$

Dessa forma, a equação 2 modela as condições de cobertura superficial do terreno e do solo, variando desde superfície muito impermeável até superfície completamente permeável.

$\mathrm{O}$ método $\mathrm{CN}$ permite mostrar o efeito das mudanças no uso e cobertura do solo sobre o escoamento superficial. Os valores de $\mathrm{CN}$ variam entre 1 e 100 (adimensional). Valores altos de $\mathrm{CN}$ indicam alto escoamento (Melesse; Shih, 2002).

Os critérios gerais propostos para elaboração do mapa dos grupos hidrológicos de solo (GHS) e as particularidades de cada ordem de solo presente na área de estudo, foram definidos de acordo com o atual Sistema Brasileiro de Classificação de Solos - SiBCS (EMBRAPA, 2006), baseado na classificação de solos tropicais brasileiros proposta por Sartori e Genovez (2011).

O mapeamento de uso do solo e cobertura da terra foi elaborado com base nos procedimentos metodológicos descritos por Jensen (2009), Novo (2010) e Moreira (2011), que utilizam como base imagens de alta resolução e técnicas de interpretação visual de imagens. As classes mapeadas foram enquadradas na classificação do método CN (TUCCI, 2001), com um total de 13 classes mapeadas na escala de 1: 4.000 e publicação em 1: 20.000.

Por fim, o processamento foi efetuado através da síntese dos mapas de uso da terra e cobertura do solo e GHS por meio da extensão HEC-GeoHMS, e a criação de uma "LookUpTable" com os valores de $\mathrm{CN}$ para bacias urbanas somados à grade de declividade. Após a obtenção da grade de $\mathrm{CN}$, o próximo passo consistiu em derivar a grade de saturação do solo (Equação 2). Posteriormente, o escoamento superficial (Q) é estimado através da IP e do parâmetro S (equação 1).

Com estes resultados foram observados, na imagem de satélite, possíveis focos de processos erosivos, tanto laminares quanto lineares e correlacionados com o mapa de escoamento superficial para análise.

\section{RESULTADOS E DISCUSSÃO}

\subsection{Caracterização do uso e cobertura da terra}


OS DESAFIOS DA GEOGRAFIA FÍSICA NA FRONTEIRA DO CONHECIMENTO

Instituto de Geociências - Unicamp

Campinas - SP

28 de Junho à 02 de Julho de 2017

A distribuição espacial do uso do solo e cobertura vegetal (figura 3) mostrou que a área de estudo é essencialmente ocupada por prados em boas condições, formados por pastagens conservadas, no entanto, algumas áreas apresentam focos erosivos. Abrange toda área de estudo, corresponde a 26,8 \% da área total, com aproximadamente 337 ha. Em seguida, as zonas florestais com boa cobertura, correspondem a 13,7 \% da área, com aproximadamente 177 ha. Estão situadas ao longo dos principais cursos d'águas e em áreas com declividade mais acentuadas. Essas áreas inviabilizam a realização de atividades antrópicas, pois são áreas destinadas à preservação, favorecendo a manutenção dessas encostas, contendo parte dos processos erosivos, além da manutenção dos recursos naturais.

As zonas residenciais, de lotes $<500 \mathrm{~m}^{2} \operatorname{com} 65 \%$ em média do terreno impermeável, são a terceira em área, correspondem $12 \%$ da área total, com aproximadamente 153 ha. Concentram-se majoritariamente na zona oeste, e em uma pequena da área norte da área de estudo, lado oeste do córrego Botafogo. Encontram-se os conjuntos habitacionais Mário Amato, Ana Jacinta, Jardim Novo Prudentino, Uep4-S.1, Uep8-S.2, caracterizados pelo grande adensamento de construções e ruas que em sua maioria são pavimentadas (com galeria pluvial), com baixa infiltração no solo.

As pastagens em mau estado de conservação foram a quarta maior classe presente na área de estudo, representando $10,7 \%$ da área total, com aproximadamente 135 ha. Concentram-se, principalmente, próximas aos arredores dos condomínios fechados, e em pequenas porções próximas da confluência do córrego Botafogo com o Cedro. Os espaços abertos, formados por gramíneas e alguns fragmentos florestais como pequenas árvores, correspondem à quinta maior classe mapeada, representando $10 \%$ da área, com aproximadamente 126 ha. Foram classificados locais com cobertura vegetal, do tipo gramínea como os parques, campos, e também solo exposto para loteamento urbano. Encontram-se distribuídas em toda área de estudo, próximo das áreas urbanas, tornando-se como uma zona de transição para o rural. $\mathrm{Na}$ borda oeste, próximo à rodovia Júlio Budisk, e arredores dos condomínios fechados, próximo à avenida Miguel Dahma, destaca-se um loteamento imobiliário sobre a nascente do córrego Botafogo. Embora com a presença da cobertura vegetal, essa ocupação requer atenção e monitoramento, pois foram observados focos de processos erosivos. Os arruamentos e estradas asfaltadas com galerias pluviais são a sexta maior classe mapeada; correspondem a $8,9 \%$ da área total, com aproximadamente 112 ha, distribuída e situada na área urbana. No entanto, a densidade de ruas por quadras na área dos conjuntos habitacionais é muito maior que na área dos condomínios. Esse fato comprova a reincidência de problemas de origem hidrometereológica nesses bairros mais adensados, como alagamentos de vias e processos erosivos induzidos pelo direcionamento do escoamento superficial.

$\mathrm{Na}$ zona leste, na margem direita ao córrego Botafogo, as zonas residenciais, com lotes $<1300 \mathrm{~m}^{2}$ com $30 \%$ em média do terreno impermeável, representam a sétima maior classe mapeada, totalizando 7,4 \%, com aproximadamente 94 ha. Essa classe, corresponde aos condomínios de alto padrão, parque 
XVII Simpósio Brasileiro de Geografia Fisica Aplicada

I Congresso Nacional de Geografia Física

\section{OS DESAFIOS DA GEOGRAFIA FÍSICA NA FRONTEIRA DO CONHECIMENTO Instituto de Geociências - Unicamp \\ Campinas - SP \\ 28 de Junho à 02 de Julho de 2017}

residencial Dhama I, II e III, e alguns ranchos e casas de campo, com terrenos amplos e abertos, presença de vegetação (arvores, gramíneas), permitindo melhor capacidade de infiltração no solo. Estão localizados na margem direita do córrego Botafogo.

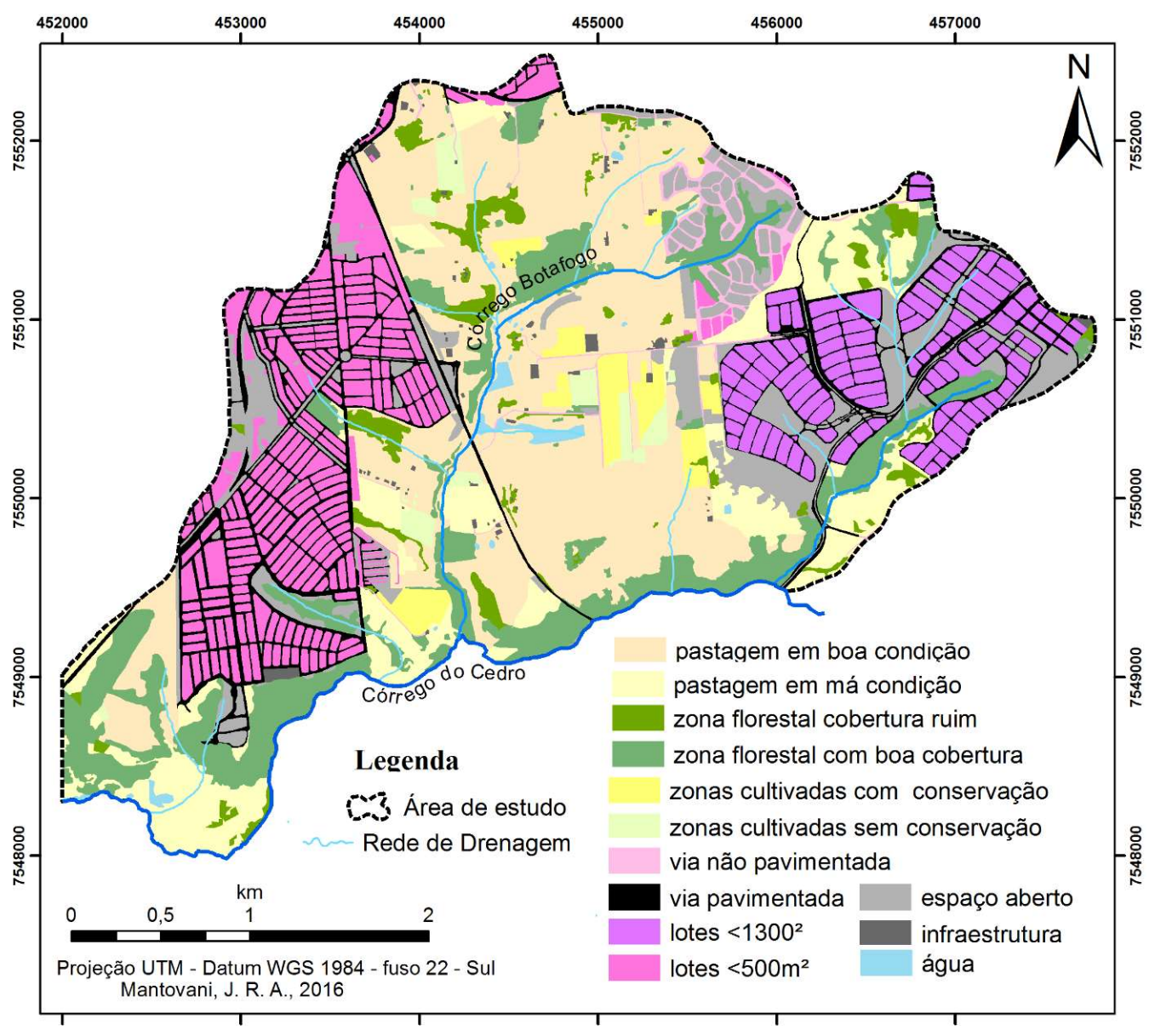

Figura 3. Mapa de uso do solo e cobertura vegetal

A caracterização do uso atual do solo na área de estudo teve como objetivo mostrar as formas de ocupação e utilização do solo, a fim de correlacioná-las com os processos que provocam degradação ambiental, associadas ao mapa de escoamento superficial.

\subsection{Mapa de grupos hidrológicos (GHS)}

O mapa de GHS (Figura 4) agrupou os solos que compõem a área de estudo em três grupos hidrológicos de solos: B, C e D. Não houve solo classificado no grupo A, muito profundos, com alta taxa de infiltração, bem drenados, com grau de resistência e tolerância à erosão.

No grupo B foram associados solos profundos, com moderada taxa de infiltração, mas com moderada resistência e tolerância à erosão. Nesse grupo foi classificado o Argissolo Vermelho Escuro Eutrófico, situado em áreas quase planas ao longo da planície de inundação do córrego Cedro, com declividades inferiores a $3^{\circ}$, inadequadas à ocupação pelos riscos de inundação. 


\section{OS DESAFIOS DA GEOGRAFIA FISICA NA FRONTEIRA DO CONHECIMENTO \\ Instituto de Geociências - Unicamp \\ Campinas - SP \\ 28 de Junho à 02 de Julho de 2017}

No grupo C, solos pouco profundos, associados a argila de atividade baixa (Tb), com baixa taxa de infiltração e baixa resistência e tolerância à erosão, contendo porcentagem significativa de argila. Foram classificados nesse grupo os Argissolos Vermelhos, Vermelhos-Amarelos e os Neossolos Flúvicos. Os dois primeiros situados em toda área de estudos sob declividades de $8^{\circ}$, com moderada suscetibilidade à erosão, com poucas restrições ao uso e ocupação do solo, e o outro, situado nas adjacências da nascente do córrego Botafogo.

No último grupo hidrológico, o $\mathrm{D}$, foi associado solo com taxa de infiltração muito baixa, proporcionando pouca resistência e tolerância à erosão, rasos, associados à mudança textural abrupta e orgânicos, gerando alto potencial de escoamento superficial. Nesse grupo, foi classificado os Gleissolos Háplicos. Observa-se que estes estão na maior parte, localizados ao longo da rede de drenagem do córrego do Cedro.

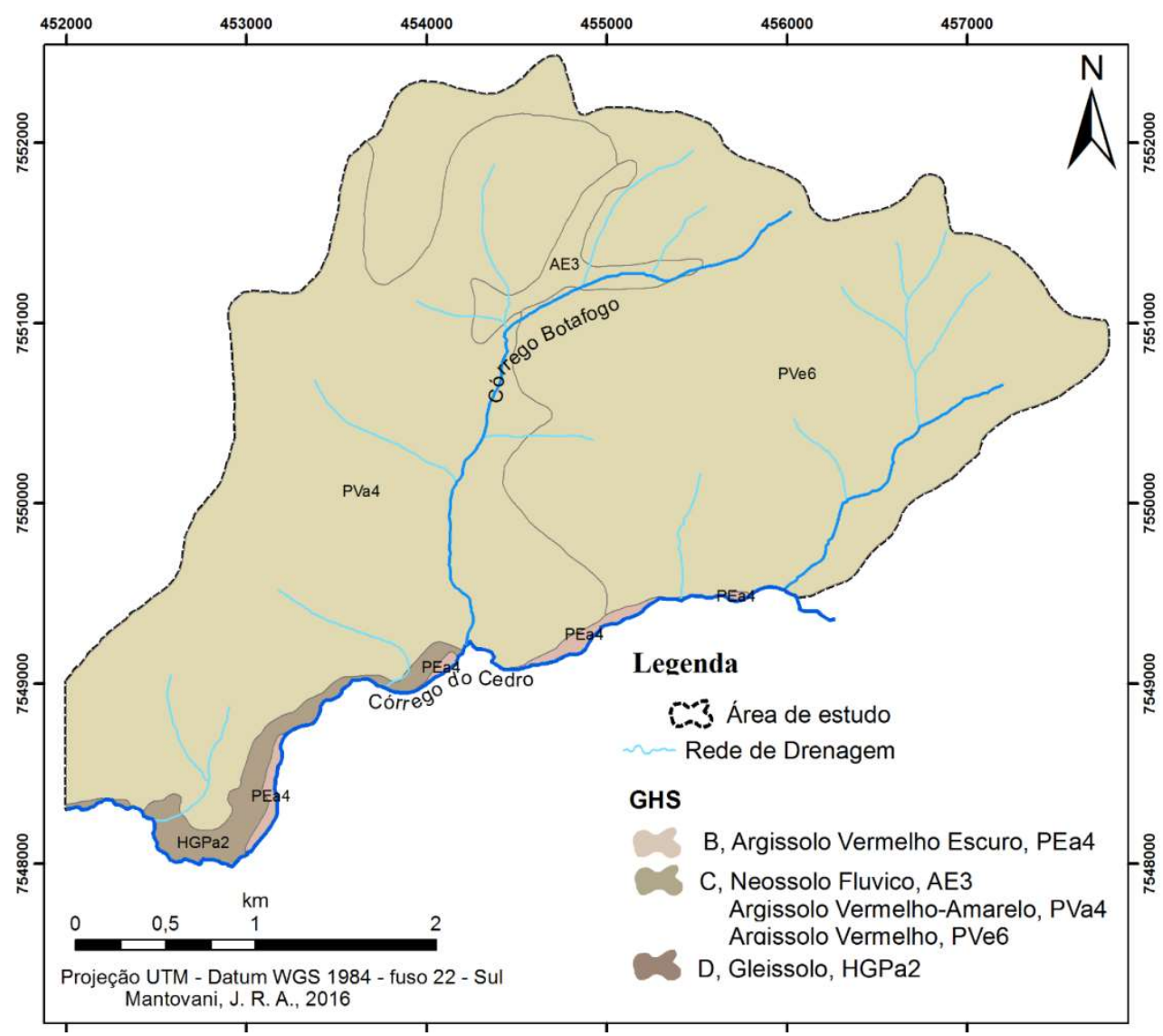

Figura 4. Mapa de grupos hidrológicos de solos (GHS)

A maior parte da bacia pertence ao grupo hidrológico C (1.214 ha) em extensão, ultrapassando os 96\% da área total, seguido pelo grupo D (30.68 ha), correspondendo a apenas 2,4\% da área de estudo. $\mathrm{O}$ predomínio desses dois grupos hidrológicos representa áreas com potencial elevado de gerar escoamento superficial e pouca capacidade e infiltração. O uso e o manejo dessas áreas exigem um estudo prévio e planejamento adequado. O grupo B (10.71 ha) correspondeu à menor classe, com pouco mais de $1,6 \%$ da área. 


\section{OS DESAFIOS DA GEOGRAFIA FISICA NA FRONTEIRA DO CONHECIMENTO \\ Instituto de Geociências - Unicamp \\ Campinas - SP \\ 28 de Junho à 02 de Julho de 2017}

\subsection{Escoamento superficial $(Q)$}

A distribuição espacial do escoamento superficial (Figura 5) mostrou que a região oeste, na margem esquerda, e leste, na margem direita do córrego Botafogo, foram as áreas com maiores intensidades de escoamento superficial. São formadas pelas zonas residenciais, com lotes $<500 \mathrm{~m}^{2}$ e $65 \%$ em média do terreno impermeabilizado, e $<1300 \mathrm{~m}^{2}$ e $30 \%$ em média do terreno impermeabilizado. Os valores de $\mathrm{Q}$ apresentados foram acima de $235 \mathrm{~mm} / \mathrm{IP}$. Como a intensidade pluviométrica considerada foi de 275,16 $\mathrm{mm}$, então, este montante escoado equivale a aproximadamente $84 \%$ do total precipitado nesses locais. Essas áreas estão sob um relevo suavemente ondulado, ocupando médias e baixas vertentes com declividade superiores a $8^{\circ}$.

$\mathrm{Na}$ área oeste, dos conjuntos habitacionais, a alta taxa de impermeabilização dos lotes e ausência de vegetação nos bairros, as vias pavimentadas contribuem para o aumento do escoamento superficial nessas áreas. Já na área que compreende os condomínios, o escoamento foi um pouco mais lento, em torno de $208 \mathrm{~mm} / \mathrm{IP}$, devido ao tamanho dos lotes, menor taxa de impermeabilização solo e presença de vegetação, além de maior presença de espaços abertos como parques. Corresponde a aproximadamente $75 \%$ do montante escoado nessas áreas. A capacidade de infiltração, irá depender das condições geoambientais.

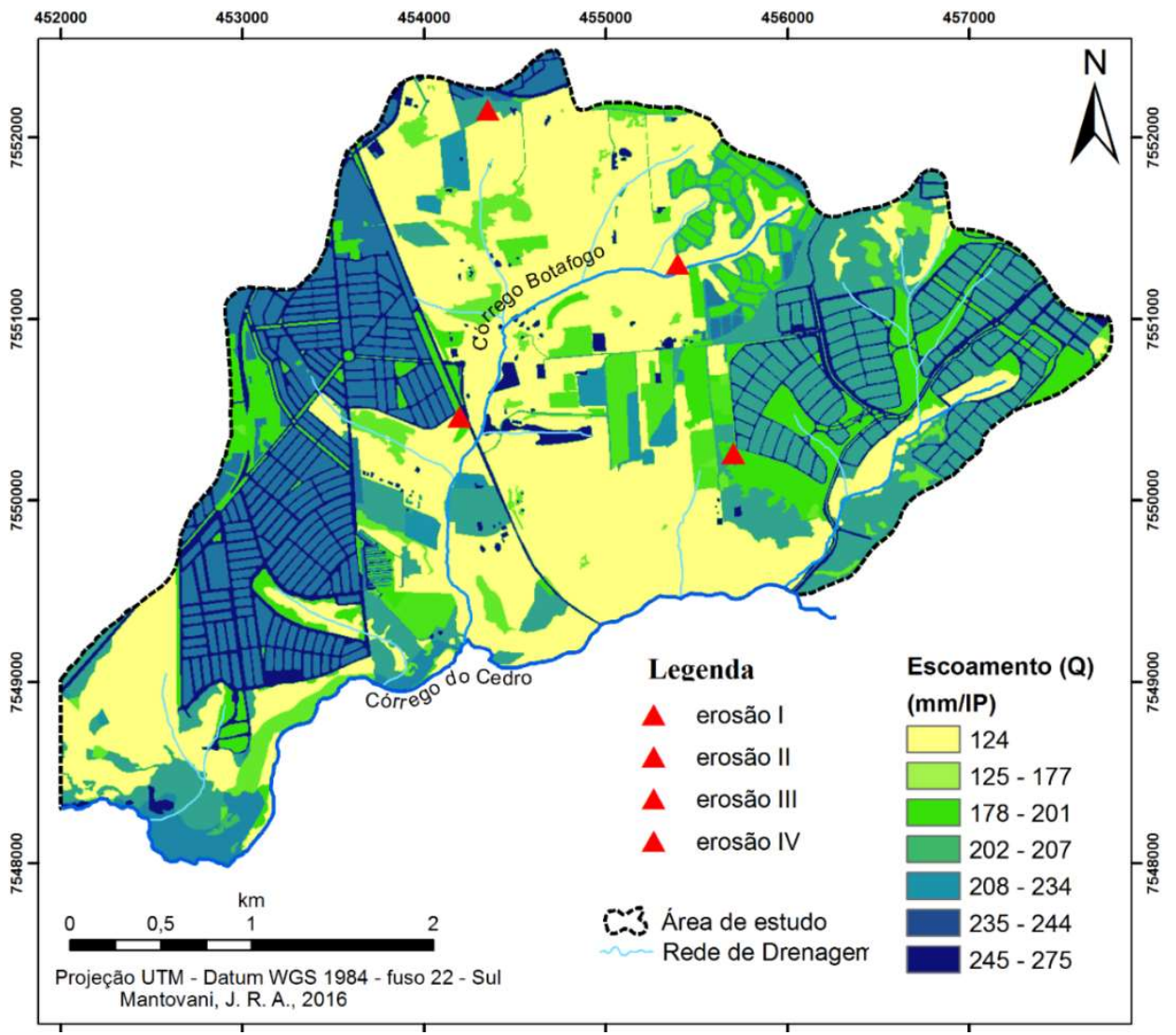

Figura 5. Mapa de Escoamento superficial (Q) 


$\begin{gathered}\text { XVII Simpósio Brasileiro } \\ \text { de Geografia Fisica Aplicada }\end{gathered}$
$\begin{aligned} & \text { I Congresso Nacional } \\ & \text { de Geografia Física }\end{aligned}$

No extremo norte da bacia, o escoamento foi elevado também, com valores acima de $208 \mathrm{~mm} / \mathrm{IP}$ Essa pequena porção urbanizada situada sobre uma alta vertente, está sob o divisor de águas que drena para bacia do Botafogo. Nessa área, foi identificado um foco erosivo (linear), induzido pelo escoamento superficial, conduzido pelas vias pavimentas e casas.

As áreas situadas nos divisores de água do córrego do Botafogo, próximas da nascente do mesmo, foram classificadas como áreas de médio potencial aos riscos. Os valores acima de $178 \mathrm{~mm} / \mathrm{IP}$ correspondem a aproximadamente $64 \%$ do total precipitado nesses locais. São as áreas situadas na porção mais elevada da bacia, as quais vêm sendo incorporada à malha urbana em expansão, contemplando loteamentos e abertura de estradas. Foram observadas uma série de focos erosivos e deposição de sedimentos no córrego Botafogo.

O restante da bacia foi classificado como de baixo potencial de riscos, pois os valores de escoamento foram relativamente baixos em comparação com o restante da bacia, ficando em torno de $124 \mathrm{~mm} / \mathrm{IP}$, totalizando o restante da área da bacia em 45 \%. Essa classificação de baixo risco está associada sobretudo ao fato dessas áreas não abrangerem áreas urbanas, sendo compostas principalmente por áreas rurais, ocupadas majoritariamente pela classe de pastagem em bom estado de conservação.

Na figura 6 são apresentados 4 focos de erosões (como amostras), os quais, acredita-se, que tenham sido causados pelo escoamento superficial induzido pelo uso inadequado do solo nessas áreas.

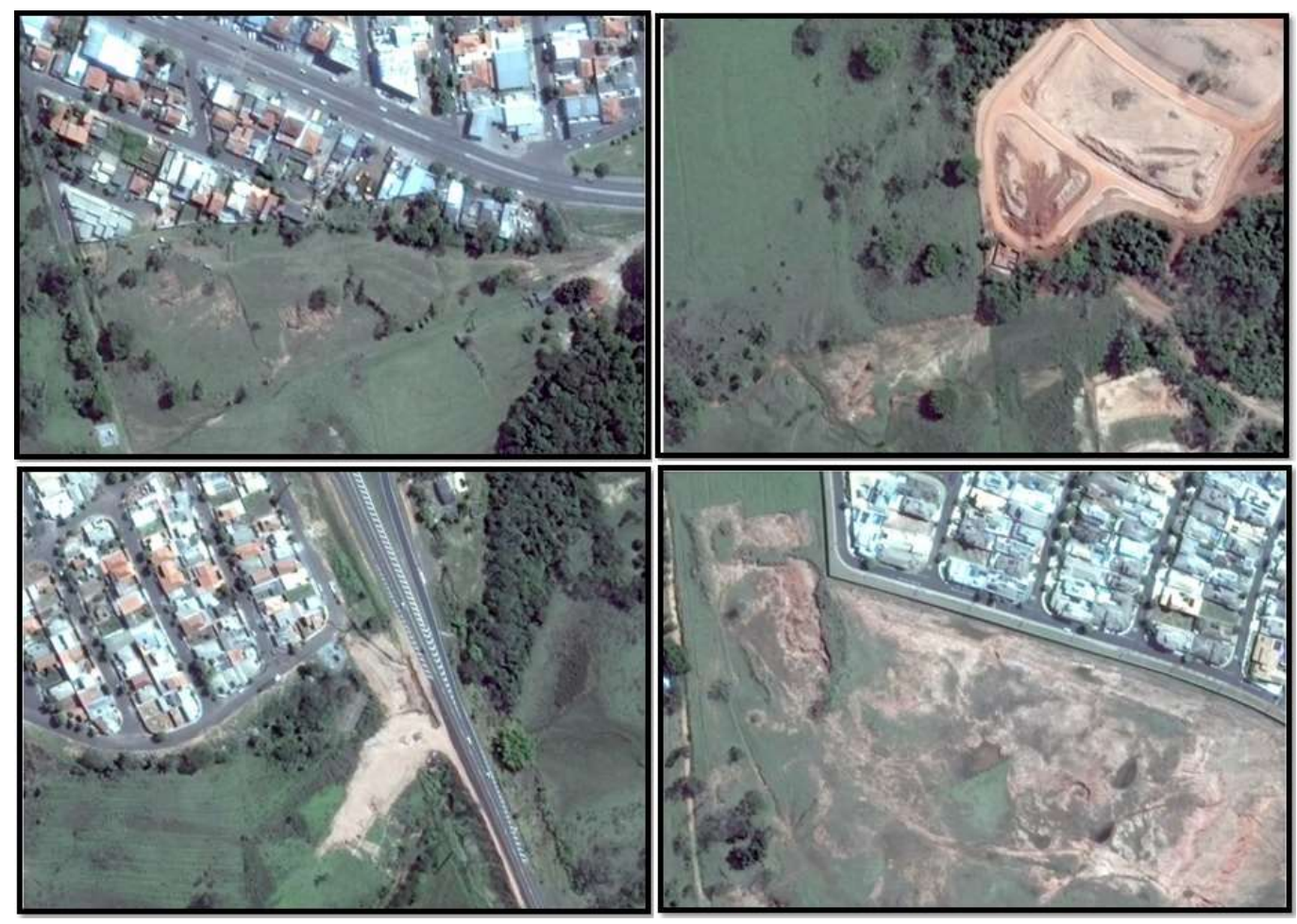

Figura 6. Amostras de focos erosivos mapeados. Imagens do Google Earth, de agosto de 2016. 
OS DESAFIOS DA GEOGRAFIA FÍSICA NA FRONTEIRA DO CONHECIMENTO

Instituto de Geociências - Unicamp

Campinas - SP

28 de Junho à 02 de Julho de 2017

Em todas as imagens, os focos de erosão foram motivados pelo uso e manejo inadequado do solo, sendo visíveis nestas figuras os processos atuantes. As áreas urbanas e as vias são importantes caminhos para a água, principalmente as vias pavimentadas, conduzindo o escoamento das águas para áreas adjacentes de altitudes inferiores. Os locais que possuem maiores declividades são mais suscetíveis à erosão, devido à aceleração do escoamento superficial da água.

Desta forma, a utilização ordenada das encostas, reduzindo-se a intensidade de ocupação e, portando, a densidade de construção em função do maior declive, é uma medida de grande importância no controle preventivo da erosão (MOTTA, 1999). A ocupação do solo deve variar conforme a declividade do terreno. Assim, quanto maior o declive do terreno, menor deve ser densidade de ocupação (DIBIESO, 2007).

\section{Conclusões}

A produção de informações espacializadas a partir de uma base cartográfica e de imagens de sensores orbitais remotos se mostrou bastante válida para possíveis análises e correlações em relação aos resultados gerados, embora houvesse a dificuldade de processar dados em diferentes escalas espaciais que tivessem precisão e qualidade espacial. A utilização um modelo hidrológico, associado a um SIG, foi adequada para o estudo do escoamento superficial, permitiu avaliar a distribuição espacial do escoamento superficial, bem como entender problemas atuais, ligados à degradação ambiental dessas áreas, uma vez que a modelagem do escoamento superficial foi simulada para o ano de 2016, de modo a simular a dinâmica atual da ocupação.

Os resultados mostraram que, de maneira geral, o comportamento do escoamento superficial se mostrou equilibrado ao longo da área de estudo. Refletiu as condições do uso e da ocupação do solo, sendo as áreas com maior degradação e presença de focos erosivos próximas da zona urbana. Os estudos realizados demonstraram a importância de se conhecer prévia e detalhadamente o meio físico da área estudada. A ocupação de novas áreas requer planejamento ambiental e manejo sobre os recursos hídricos, pois constataram-se muitos focos de erosão, associados ao escoamento superficial. Além de alguns locais ao longo dos canais da rede de drenagem, inclusive o córrego Botafogo e Cedro, em estado de degradação ou assoreamento.

A finalidade de identificar os padrões de escoamento superficial, tanto para avaliar o estado de conservação ambiental da bacia, quanto para prevenção de impactos, é um importante instrumento para subsidiar futuros trabalhos de gestão e planejamento ambiental. Dessa forma, pode-se agregar informações à base de dados visando precauções com futuras obras, ocupações e intervenções a serem desenvolvidas, a fim da manutenção positiva do meio ambiente e, principalmente, evitar danos à sociedade em geral, especificamente na bacia do Cedro. 


\section{Referências Bibliográficas}

BARRIOS, N. A. Z.; SANT'ANNA NETO, J. L. A circulação atmosférica no extremo oeste paulista. Boletim climatológico, Presidente Prudente, v.1, n.1, p.8-9, março 1996.

CARVALHO, W.A (Coord.). Levantamento semidetalhado dos solos da bacia do rio Santo Anastácio-SP. Presidente Prudente, SP: FCT UNESP, (Boletim científico, n.2) 1997.

CREPANI, E.; MEDEIROS, J. S.; FILHO, P. H.; FLORENZANO, T. G.; DUARTE, V.; BARBOSA, C. C. F. Sensoriamento Remoto e Geoprocessamento Aplicados ao Zoneamento Ecológico-Econômico e ao Ordenamento territorial. São José dos Campos: SAE/INPE, 2001.

DIBIESO, E. P. Planejamento ambiental da bacia hidrográfica do córrego do Cedro - Presidente Prudente/SP. Dissertação (Mestrado em Geografia) - F.C.T./UNESP. Presidente Prudente, 2007.

EMBRAPA - Sistema Brasileiro de Classificação de Solos. $2^{\mathrm{a}}$ Edição, Embrapa Solos, Rio de Janeiro-RJ, 306p. 2006.

EMPLASA. Arquivos digitais do modelo digital de superfície do Projeto de Atualização Cartográfica do Estado de São Paulo - "Projeto Mapeia São Paulo". Produtos de levantamento aerofotogramétrico de 2010-2011. Instituto Geológico. Titularidade: Empresa Paulista de Planejamento Metropolitano S/A EMPLASA. Contrato de Licença de Uso 038/12, estabelecido entre e SMA EMPLASA. 2010.

FRANCISCO, C. F. Análise ambiental e consequências do desmatamento no município de Presidente Prudente no período de 1917 a 1986. Dissertação (mestrado em geografia), UNESP - IGCE. Rio Claro, 1989.

HEC - Hydrologic Engineering Center. HEC-GeoHMS: geospatial hydrologic modeling extension. US Army Corps of Engineers. User's Manual. Version 4.2. 2009. Disponível em <www.hec.usace.army.mil/software/hecgeohms>. Acesso em 02 de Agosto de 2012.

MELESSE, A.M.; Shih, S.F. Spatially distributed storm runoff depth estimation using Landsat images and GIS. Computers and Electronics in Agriculture, v. 37, n. 1-3, p. 173-183, 2002.

MOTTA, S. Urbanização e meio ambiente. Rio de Jeneiro: ABES, 1999.

NUNES, J. O. R., FREIRE, R., \& PEREZ, I. U. (2006). Mapeamento geomorfológico do perímetro urbano do município de Presidente Prudente - SP. In: Anais do VI Simpósio Nacional de Geomorfologia (p. 1-11). Goiânia: UFG.

SARTORI, A.; GENOVEZ, A.M; LOMBARDI NETO, F. Classificação Hidrológica de Solos Brasileiros para a Estimativa de Chuva Excedente com o Método do Serviço de Conservação do Solo dos Estados Unidos -Parte 1: Classificação. Revista Brasileira de Recursos Hídricos, v.10, p. 05-18, 2011. 
STEIN, D.P. Avaliação da degradação do meio físico - Bacia do rio Santo Anastácio, oeste paulista. Rio Claro, 1999. Tese (Doutorado em Geociências) - Instituto de Geociências e Ciências Exatas - UNESP.

TUCCI, C.E.M. Hidrologia: ciência e aplicação. 2 ed. Porto Alegre: UFRGS: ABRH. 2001. 943 p. 